\title{
Rate of increase in pulmonary distensibility in a longitudinal study of smokers
}

\author{
H JOHN H COLEBATCH, CLIFFORD K Y NG
}

From the Department of Respiratory Medicine, University of New South Wales, and Prince Henry Hospital, Little Bay, New South Wales, Australia

ABSTRACT To examine the hypothesis that an abnormally rapid increase in pulmonary distensibility occurs in cigarette smokers, 39 adult smokers ( 24 men), mean age 47 (SD 8) years, who were not disabled were studied on two occasions over a mean interval of 3.5 (SD 0.5) years. Exponential analysis of static pressure-volume data obtained during deflation of the lungs gave the exponent $\mathrm{K}$, an index of distensibility. Total lung capacity (TLC) was measured in a body plethysmograph. At entry into the longitudinal study mean values for $\mathrm{K}$ and static recoil pressure in the 39 smokers available for follow up were similar to those obtained in the original group of 101 smokers (73 men), mean age 42 (SD 11) years, in the cross sectional study. Over the interval of the study, $\ln K$ and TLC increased and $\mathrm{FEV}_{1}$ decreased at rates greater than those found in a previous longitudinal study of 34 non-smokers (24 men), mean age 42 (SD 15) years. In the longitudinal study of smokers the observed changes in $\mathrm{K}$ and in recoil pressure over the interval of study were greater than the values obtained from the regression slopes found in the cross sectional study of smokers. On the basis of the regression model used previously in the longitudinal study of non-smokers, the age coefficient for $\ln \mathrm{K}$ was greater than that found in the non-smokers $(\mathrm{p}<0.01)$. The regression model also showed that the slope of $\ln \mathrm{K}$ on age increased in older subjects. Because $\mathrm{K}$ is related to peripheral airspace size, a rapid rate of increase in $\mathrm{K}$ identifies smokers in whom airspace size is increasing abnormally rapidly. In this study the rate of increase in $\mathrm{K}$ and the variation between subjects was sufficient to explain the magnitude of the increased pulmonary distensibility found in cigarette smokers who present with emphysema.

According to the elastase hypothesis for the development of emphysema, ${ }^{2}$ a relative increase in elastolytic degradation of lung connective tissue produces an increase in the size of peripheral airspaces and breakdown of alveolar tissue. The observations of Thurlbeck ${ }^{34}$ and others ${ }^{56}$ show that increases in lung volume and in peripheral airspace size are found in lungs with minor or equivocal evidence of tissue destruction, from which it has been inferred that the increase in volume is independent of the "lesions of emphysema" (which are defined partly in terms of alveolar wall destruction). An alternative view is that in the process leading to the anatomical changes recognised as "emphysema" an increase in the size of airspaces precedes the breakdown of alveolar tissue. If

Address for reprint requests: Dr H J H Colebatch, Department of Medicine. University of New South Wales. Prince Henry Hospital, Little Bay, New South Wales 2036, Australia.

Accepled 3 November 1987 the latter were true, it should be possible to show that an increase in the size of airspaces occurs at an accelerated rate in some smokers. We expect also that an increase in the size of airspaces would be likely to begin in some smokers within the first few years of smoking and would progress at different rates for different individuals.

The size of airspaces in the lungs is the major determinant of pulmonary distensibility. ${ }^{78}$ By studying pulmonary distensibility therefore the gradual increase in airspace size in cigarette smokers can be followed. Pulmonary distensibility is quantified by exponential analysis of static pressure-volume (PV) data obtained during deflation of the lungs. ${ }^{9}$ The exponent $\mathrm{K}$ is an index of distensibility, which is independent of lung size and independent of sex. ${ }^{10}$ The index $\mathrm{K}$ relates directly to a morphometric estimate (mean linear intercept, $\mathrm{Lm}$ ) of average airspace size in excised human lungs, whether normal or emphysematous, as well as in the lungs of several other mammals. ${ }^{8}$ Through its influence on surface forces the 
size of airspaces is the major determinant of $\mathrm{K} .{ }^{8}$ This hypothesis was supported by the finding in healthy subjects that the rate of increase in $\mathrm{K}$ with age corresponds to the rate of increase in Lm with age in excised human lungs." In a previous cross sectional study of cigarette smokers who were not disabled $\mathrm{K}$ increased with age more rapidly than in non-smokers, suggesting that the size of airspaces also increased at an unusually rapid rate. ${ }^{12}$

The present longitudinal study of smokers was undertaken to obtain a direct estimate of the rate of increase in $\mathrm{K}$ (and therefore of $\mathrm{Lm}$ ) in individual smokers and to test the following hypothesis. If the increase in the size of airspaces in the lungs is a gradual process extending over many years, as is implicit in the elastase hypothesis, ${ }^{1314}$ then $\mathrm{K}$ should increase abnormally rapidly in some smokers and at a rate sufficient to account for values obtained in patients presenting with emphysema in their sixth decade. In other smokers, presumably those who maintain a normal elastase-antielastase balance or who can repair elastin damage more effectively, the rate of increase in $\mathrm{K}$ should be similar to that found in healthy nonsmokers.

\section{Methods}

\section{SUBJECTS}

The 39 subjects ( 24 men and 15 women) included in the present study were regular cigarette smokers without established lung disease and all were able to maintain normal activity. They were selected from 101 subjects who had been included in a cross sectional study. ${ }^{12}$ Of these 101 subjects, 10 had become ex-smokers, three refused to take part in a second study, and one had died from an accident. The remaining 48 subjects from the cross sectional study did not reply or could not be traced. All subjects smoked more than 15 cigarettes a day, with a mean consumption of 33 (SD 14, range 1580) cigarettes a day, starting from the age of 18 (SD 4, range 9-32) years. The interval between the first and the second study averaged $3 \cdot 5$ (SD $0 \cdot 5$, range $2 \cdot 8-5 \cdot 2$ ) years. All subjects freely consented to these studies.

\section{PRESSURE-VOLUME DATA}

Static pressure-volume data were obtained during several interrupted deflations of the lungs from total lung capacity (TLC) with a computerised measurement system. ${ }^{15}$ Transpulmonary pressure $(\mathrm{PL})$ was measured with an oesophageal balloon (length $10 \mathrm{~cm}$, gas volume $0.5 \mathrm{ml}$ ) and a Statham differential strain gauge (PM131TC). For both studies in a given subject the distance from the external nares to the tip of the balloon was the same. The change in lung volume from TLC was obtained by electrical integration of flow at the mouth with correction for gas compression near TLC but not at lower lung $\stackrel{\vec{F}}{\vec{F}}$ volumes..$^{10}$ After each deflation pressure-volume data $\underset{0}{0}$ were displayed on a graphics terminal (Tektronix 믐 4006).

A single exponential function of the form $\stackrel{\mathrm{D}}{\stackrel{\mathrm{D}}{\Omega}}$ where $V$ is lung volume, $P$ is static recoil pressure, and $\mathrm{A}, \mathrm{B}$, and $\mathrm{K}$ are constants, was fitted to the pressurevolume data from TLC to a lower volume limit, $\overrightarrow{\vec{\omega}}$ usually in the range of $50-60 \%$ TLC (mean $56 \%$, SD $5 \%$ TLC), in such a way as to exclude data points $\vec{x}$ systematically shifted to lower pressures relative to an exponential curve. ${ }^{9}$ On average, 32.3 (SD 5.5) pres- $\omega$ sure-volume points were used to define the exponential function. In all studies in a given subject the exponen- $v$ tial function was fitted to pressure-volume data over 윽 the same volume range.

The exponential constant $\mathrm{K}$ describes the shape of the pressure-volume curve independently of TLC, $\mathrm{A}$ is the volume asymptote, and B is the difference between $\stackrel{\sigma}{\supset}$ A and the volume at zero recoil pressure. The distribu- $\vec{\oplus}$ tion of the original pressure-volume data about the $\stackrel{\infty}{\infty}$ derived curve was quantified by the ratio of residual variance divided by the total variance for volume. Average residual variance was $1.0 \%$ (SD $0.6 \%$ ) in the initial study and was similar in the second study.

PL during a sustained maximum inspiratory effort at $\stackrel{\circ}{\varnothing}$ full inflation (maintained for approximately one second, PLmi) was measured directly and was the mean of the four highest values. Static recoil pressure at $90 \%$ of TLC $\left(\mathrm{PL}_{90}\right)$ was derived from the exponential function.

\section{LUNG VOLUMES}

TLC and the maximum expiratory flow-volume curve (MEFV) were obtained with a body plethysmograph and associated electronic equipment (Pulmostar Compact, Fenyves and Gut, Basel) connected via an analogue to digital converter to the computerised measurement system..$^{10}$ In this pressure-flow plethysmograph gas flow between the box and its surround- $\frac{7}{0}$ ings and gas flow at the mouth were measured with Fleisch pneumotachometers (No 3). When this was $N$ tested with an oscillating flow, the signals representing $N$ mouth volume and box volume (obtained by electrical $N$ integration of flow) were in phase up to $10 \mathrm{~Hz}$. To correct for non-linearity of the Fleisch pneumotachometer the volume obtained by integration of forced $\stackrel{\varrho}{\subset}$

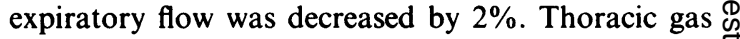
volume was obtained by a Boyle's law method with $\stackrel{+}{+}$ computerised sampling and a breathing frequency of about $1 \mathrm{~Hz} .^{12}$ Immediately after the measurement of $\underset{\mathbb{D}}{ }$ thoracic gas volume, the subject inspired maximally $\stackrel{\odot}{\overparen{D}}$ and the inspired volume was added to thoracic gas $\cong$ volume to obtain TLC. The final value used for TLC was the mean of three or four measurements. 
For analysis of the increase in $\ln \mathrm{K}$ with age we used the statistical model developed by McGilchrist et al, ${ }^{1718}$ which has the following form:

$\ln \mathrm{K}=\mathrm{a}+\mathrm{b}_{1} \times$ age $+\mathrm{b}_{2} \times$ age $\times \Delta$ age $+C+\mathrm{E},(2)$ where $a$ is a constant, $b_{1}$ is the age coefficient, age is the age in years at entry to the study, $\Delta$ age is the elapsed time since entry, $b_{2}$ shows whether the age coefficient changes over the period of observation, $C$ is a random variable representing the contribution to $\ln \mathrm{K}$ peculiar to an individual subject, and $\mathrm{E}$ is the individual error term. The ratio of the variance of $C$ to the variance of $E$ tests whether the difference between subjects exceeds the variance attributable to an individual. This is a mixed model solved by maximum likelihood. It resembles a mixed ANOVA with two random effects. The advantage of this model is that it allows for a variable number of observations in different individuals to be included as well as for a significant difference in $\ln \mathrm{K}$ between individuals. For these reasons we used it previously to analyse the change in $\ln K$ in a longitudinal study of healthy non-smokers." Each observation is entered as $\ln \mathrm{K}$ and related to age and the years since entry to the study. We used this model to define how $\ln \mathrm{K}$ changes with age and not to imply causal relationships.

For all lung volumes the BTPS value was used. Linear regression, covariance analysis of linear regression, determination of $\mathrm{R}$, and Student's $t$ test were performed as described by Snedecor. ${ }^{16}$ Results are compared with those obtained in a cross sectional study of smokers ${ }^{12}$ and in a longitudinal study of healthy non-smokers." Where the hypothesis being tested is that a difference between smokers and nonsmokers for a given parameter arises because smoking increases the change a single tailed $t$ test has been used. In cross sectional studies of smokers ${ }^{12}$ and non-smok$\mathrm{ers}^{10}$ there was no sex difference for $\mathrm{K}$ or for the slopes of the regressions on age for $\mathrm{PLmi}_{\mathrm{L}}$ and $\mathrm{PL}_{90}$; in the present study therefore these values for men and women have been combined.

\section{Results}

At the time of the first study (table 1) the 39 smokers to be studied longitudinally were similar in age to the non-smokers studied longitudinally" and, on average, a little older than the 101 smokers previously studied cross sectionally. At entry to the present study mean values obtained for $\mathrm{K}, \ln \mathrm{K}$, and static recoil pressure (table 2) were similar to values obtained in the smokers in the cross sectional study. For each measurement the change over the interval of study was highly significant $(p<0.005)$. Individual values for $K$ are shown in fig 1 . The rate of increase in $\mathrm{K}$ or decrease in recoil pressure over the interval of study was greater than the values obtained from the respective regression slopes in the
Table 1 Anthropometric data (means with standard deviations in parentheses) at entry for longitudinal studies in smokers (present study*) and in non-smokers" and in a cross sectional study of smokers ${ }^{12}$ (numbers of subjects in square brackets)

\begin{tabular}{|c|c|c|c|c|c|}
\hline \multirow[b]{2}{*}{ Sex } & \multicolumn{3}{|c|}{ Longitudinal } & \multirow{2}{*}{\multicolumn{2}{|c|}{$\begin{array}{l}\begin{array}{l}\text { Cross } \\
\text { sectional }\end{array} \\
\text { Smoker }\end{array}$}} \\
\hline & Smo & ker & Non-smoker & & \\
\hline $\begin{array}{l}\underset{M}{\text { Age }(y)} \\
\mathbf{F} \\
M+F\end{array}$ & $\begin{array}{r}{[24]} \\
{[15]} \\
{[159]}\end{array}$ & $\begin{array}{l}47 \dagger(9) \\
45 \quad(7) \\
47 \dagger(8)\end{array}$ & $\begin{array}{ll}{[24]} & 44(15) \\
{[10]} & 37(15) \\
{[34]} & 42(15)\end{array}$ & $\begin{array}{r}{[73]} \\
{[28]} \\
{[101]}\end{array}$ & $\begin{array}{l}42(11) \\
43(8) \\
42(11)\end{array}$ \\
\hline $\begin{array}{c}\mathrm{Ht}(\mathrm{cm}) \\
\stackrel{\mathrm{M}}{\mathrm{F}}\end{array}$ & & $\begin{array}{ll}177 & (9) \\
163 & (6)\end{array}$ & $\begin{array}{l}178(5) \\
164(8)\end{array}$ & & $\begin{array}{l}176(8) \\
163(5)\end{array}$ \\
\hline $\begin{array}{l}\text { Wt (kg) } \\
\mathbf{M} \\
\mathbf{F}\end{array}$ & & $\begin{array}{lr}78 & (13) \\
58 & (8)\end{array}$ & $\begin{array}{l}76(10) \\
64(10)\end{array}$ & & $\begin{array}{l}77(12) \\
61 \quad(9)\end{array}$ \\
\hline
\end{tabular}

*The smokers in the longitudinal study are a subsample of the cross sectional study of smokers.

$+p<0.05:$ significance of the difference from the value for the cross sectional study.

Table 2 Exponential analysis of pressure-volume data (means with standard deviations in parentheses) for 39 smokers studied twice (present study) and for a cross sectional study of 101 smokers $^{12 *}$

\begin{tabular}{|c|c|c|c|}
\hline & \multicolumn{2}{|c|}{ Longitudinal studies } & \multirow{2}{*}{$\begin{array}{l}\text { Cross } \\
\text { sectional } \\
\text { study }\end{array}$} \\
\hline & Initial & Final & \\
\hline $\begin{array}{l}\mathrm{K},\left(\mathrm{kPa}^{-1}\right) \\
\ln \mathrm{K},\left(\mathrm{kPa}^{-1}\right)\end{array}$ & $1.62(0.68)$ & $1.84(0.81)$ & $1.59(0.61)$ \\
\hline $\begin{array}{c}\times 10 \\
\mathrm{PLmi}_{(\mathrm{kPa})} \\
\mathrm{PL}_{90}(\mathrm{kPa})\end{array}$ & $\begin{array}{l}4.08(0.38) \\
3.30(1.17) \\
1.34(0.40)\end{array}$ & $\begin{array}{l}5.35(0.37) \\
2.89(0.98) \\
1.21(0.36)\end{array}$ & $\begin{array}{l}4.05(0.34) \\
3.37(1.10) \dagger \\
1.37(0.37)\end{array}$ \\
\hline
\end{tabular}

*The change from the initial to the final study (over an average of 3.5 (SD 0.5) years was significant in each case $(p<0.005)$. Values for the initial study and the cross-sectional study are similar. +For 73 men.

K-index of lung distensibility; Pumi-static recoil pressure at maximum inspiration; $\mathrm{PL}_{90}$-recoil pressure at $90 \%$ of total lung capacity.

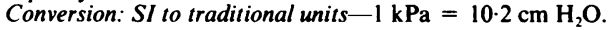

cross sectional study of smokers (table 3 ). The rate of increase in $\mathrm{K}$ and $\ln \mathrm{K}$ and the rate of decrease in PLmi were also greater than the values found in the longitudinal study of non-smokers, but the rate of decrease in $\mathrm{PL}_{90}$ was similar in the two studies.

The final form of the regression model used to estimate the increase in In $\mathrm{K}$ with age (table 4) was reached after we had tested several possible models. The term age $\times \Delta$ age (equation 2 ) decreased the -2 In (likelihood) estimate from the 126.92 obtained with a regression on age alone to $109 \cdot 15$. The decrease of $17 \cdot 77$ was highly significant $\left(\chi^{2}\right.$ test with one degree of freedom, $p<0.005$ ) and therefore improved the fit of the model. The addition of the term $b_{3} \times \Delta$ age to equation 2 gave a value for $b_{3}\left(5.31 \times 10^{3}\right.$, SEM 41.6 


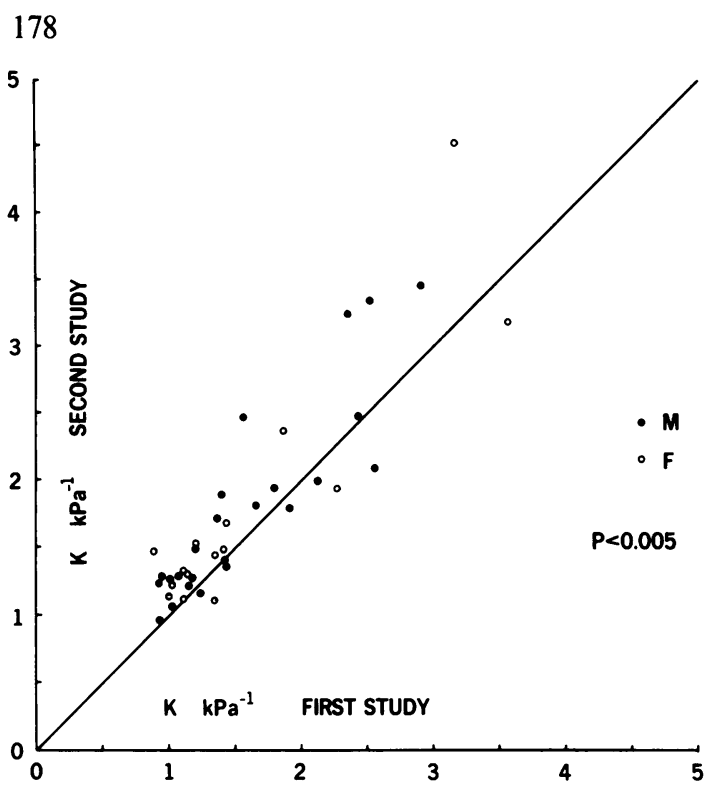

Fig 1 Values for pulmonary distensibility ( $K$ ) for 24 male $(M)$ and 15 female ( $F$ ) smokers for the first study (abscissa) and the second study (ordinate). K increased significantly over the interval between these studies. The line of identity is shown.

$\left.\times 10^{3} ; \mathrm{p}>0 \cdot 5\right)$ that was insignificant; it changed the estimate of the coefficient for the age $\times \Delta$ age term $\left(b_{2}\right)$ from $7.68 \times 10^{-4}$ to $8.80 \times 10^{-4}$, which was less than one standard error of the estimate for $b_{2}$. The $\Delta$ age term was therefore omitted from the final regression model.

In the smokers the estimate for the rate of increase in $\ln \mathrm{K}$ with age at entry to the study $\left(2.26 \times 10^{-2} /\right.$ yearage coefficient, $b_{1}$ in table 4) was greater than the corresponding value obtained in the longitudinal study of non-smokers ${ }^{11}\left(9.02 \times 10^{-3} /\right.$ year, SEM $1.77 \times$ $\left.10^{-3}, \mathrm{p}<0.01\right)$, but it did not differ significantly from the age coefficient in the cross sectional study of

smokers $(\mathrm{p}>0 \cdot 1)$ or from $\Delta \ln \mathrm{K} /$ year in smokers ( $\mathrm{p}$ $>0 \cdot 1$; table 3$)$. The coefficient $\left(b_{2}\right)$ for the interaction term was also significant and shows that in older subjects $\ln \mathrm{K}$ increased at a slightly greater rate than that given by $b_{1}$. The significant variance ratio (table 4 ) shows that values for $\ln \mathrm{K}$ differed significantly between subjects.

The regression coefficient obtained from linear regression of the pooled values for $\ln \mathrm{K}$ (two observations per subject) in the longitudinal studies of smokers and of non-smokers was greater in smokers $(2.43$ $\times 10^{-2}$ year, SEM $0.469 \times 10^{-2} /$ year) than in nonsmokers $\left(1.02 \times 10^{-2} /\right.$ year, SEM $0.136 \times 10^{-2} /$ year; $p$ $<0.005)$ and close to the value given for $b_{1}$ in table 4 . This estimate of the regression coefficient from the $v+$ longitudinal study of smokers was also greater than 은 that obtained in the cross sectional study of smokers (table 3). After allowance has been made for age, the value of $\ln \mathrm{K}$ did not show a significant relationship to the duration of smoking $(\mathrm{F}=0.872)$.

Individual values for TLC in the two studies are $\overrightarrow{0}$ shown in figure 2. Over the interval of study FRC and $\infty$ TLC increased; VC, FEV , the ratio of FEV, to FVC, and maximum mid expiratory flow decreased (table 5). The changes were similar in men and women and only the pooled results are given. The rate of increase in TLC and decrease in FEV ${ }_{1}$ were greater in the smokers in this study than in the longitudinal study of nonsmokers $^{11}$ ( $p<0.05$ and $<0.001$ respectively), but the changes in FRC and VC did not differ significantly in the two studies. The remaining values in table 5 could not be compared with findings in the non-smokers.

\section{Discussion}

The subjects included in our previous cross sectional study of cigarette smokers appeared to be representative of a working population of smokers without overt disability, ${ }^{12}$ and the subsample available for the present longitudinal study showed values similar to those obtained in the larger, cross sectional study. By

Table 3 Annual changes in pulmonary distensibility in longitudinal and cross sectional studies (means with standard errors in $\mathrm{N}$ parentheses)

\begin{tabular}{|c|c|c|c|}
\hline & \multicolumn{2}{|l|}{ Longitudinal* } & \multirow{2}{*}{$\begin{array}{l}\text { Cross sectional smokers } \\
\text { (regression slopes) }\end{array}$} \\
\hline & Smokers (difference/y) & Non-smokers (difference/y) & \\
\hline $\begin{array}{l}\mathrm{K}\left(\mathrm{kPa}^{-1}\right) \times 10^{2} \\
\ln \mathrm{K}\left(\mathrm{kPa} \mathrm{a}^{-1}\right) \times 10^{2} \\
\mathrm{PLmi}(\mathrm{kPa}) \times 10 \\
\mathrm{PL}_{90}(\mathrm{kPa}) \times 10^{2}\end{array}$ & $\begin{array}{r}6.63+\S(1.89) \\
3.67 \ddagger \S(0.81) \\
-1.21+\S(0.24) \\
-3.98 \S(0.69)\end{array}$ & $\begin{array}{r}2.94(0.65) \\
1.83(0.40) \\
-0.72(0.16) \\
-3.20(0.55)\end{array}$ & $\begin{array}{l}2.25(0.54) \\
1.17(0.30) \\
-0.41(0.1) \\
-1.68(0.33)\end{array}$ \\
\hline \multicolumn{4}{|c|}{$\begin{array}{l}\text { *For the longitudinal studies the difference per year between the final and the first study was calcula } \\
\text { obtained. } \\
+\mathrm{p}<0.05 \text {. } \\
+\mathrm{p}<0.01 \text { : significance of the difference from the corresponding value in non-smokers (single tail test). } \\
\$ \mathrm{p}<0.05 \text {, from corresponding regression slope in smokers (two tail test). } \\
\text { ॥For } 73 \text { men. } \\
\text { Abbreviations as in table } 2 \text {. }\end{array}$} \\
\hline
\end{tabular}


Table 4 Regression of $\ln K\left(\mathrm{kPa}^{-1}\right)$ on age (years) at entry into the longitudinal study*

\begin{tabular}{lcll}
\hline & Estimate & $S E$ & $p$ \\
\hline $\mathrm{a} \times 10$ & -6.42 & 3.08 & $<0.05$ \\
$\mathrm{~b}_{1} \times 10^{2}$ & $2.26 \dagger$ & 0.653 & $<0.001$ \\
$\mathrm{~b}_{2} \times 10^{4}$ & $7.68 \ddagger$ & 1.64 & $<0.001$ \\
$(\operatorname{Var} \mathrm{C}) /($ Var E) & $6.53 \S$ & 2.3 & $<0.01$ \\
$\left(\right.$ Var E) $\times 10^{2}$ & 1.44 & & \\
\hline
\end{tabular}

*Values from $\ln \mathrm{K}=\mathrm{a}+\mathrm{b}_{1} \times$ age $+\mathrm{b}_{2} \times$ age $\times \Delta$ age $+C+\mathrm{E}$, where $b_{1}$ is the age coefficient, $\Delta$ age is the elapsed time since entry, $b_{2}$ tests whether the age coefficient changes with time, $C$ is the contribution to $\ln \mathrm{K}$ peculiar to an individual subject, and $\mathrm{E}$ is the individual error term.

†Significantly greater than the value obtained for a longitudinal study of 34 non-smokers, $p<0.01$ (single tail test).

$\ddagger$ The age coefficient for $\ln K$ increases over the years of study.

$\S$ Values for $\mathrm{ln} \mathrm{K}$ differ significantly between individual smokers.

Var-variance.

Conversion: SI to traditional units-To convert $\mathrm{kPa}^{-1}$ to $\mathrm{cm}_{2} \mathrm{H}^{-1}$ subtract $\ln 10 \cdot 2$ from the value given for $a$.

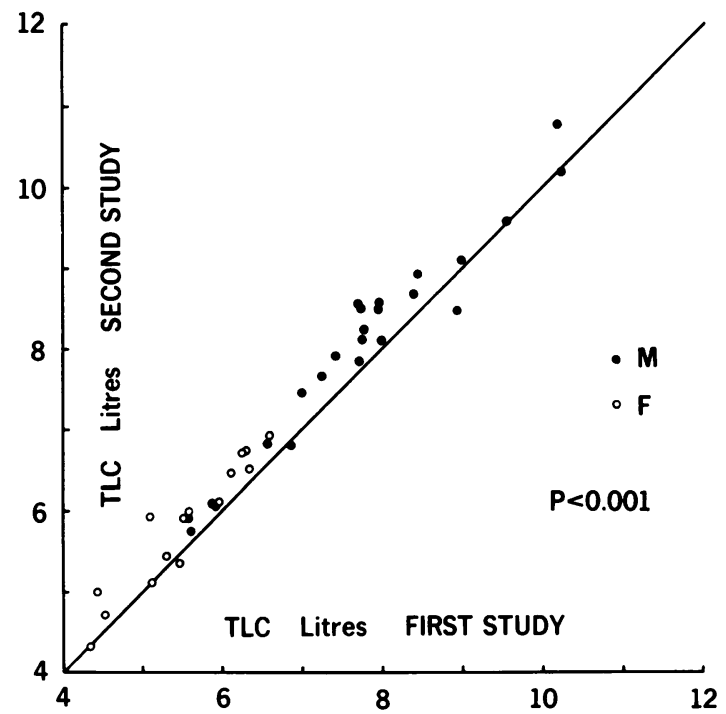

Fig 2 Values for total lung capacity (TLC) for 24 male $(M)$ and 15 female $(F)$ smokers for the first study (abscissa) and the second study (ordinate). TLC increased significantly over the interval between these studies. The line of identity is shown. excluding subjects with established lung disease, however, we have probably underestimated the effects of heavy smoking in a random sample of the population.

The rate of decrease in $\mathrm{FEV}_{1}$ in the present study was greater than that obtained in a longitudinal study of non-smokers" and similar to that reported for smokers ( $>15$ cigarettes/day) by Fletcher and Peto. ${ }^{19}$ The decrease in VC was relatively smaller than the decrease in $\mathrm{FEV}_{1}$ - a result consistent with an increase in TLC. ${ }^{20}$ The rates of increase in TLC and in FRC reported here are similar to those found by Corbin et al in their longitudinal study of smokers. ${ }^{21}$ The increase in TLC documented here is unlikely to be related to technical factors, because all tests were performed with the same equipment. It is consistent with the increased TLC found in cigarette smokers with emphysema. ${ }^{36}$

Pulmonary distensibility increased and elastic recoil pressures decreased more rapidly in the present group of smokers than in the non-smokers studied previously." Static recoil pressure is inversely related to $\mathrm{K}$, so the decreases in PLmi and $\mathrm{PL}_{90}$ complement the observed increase in $\mathrm{K}$. The rate of decrease in $\mathrm{PL}_{90}$ was greater in smokers than in non-smokers but the difference did not reach statistical significance (table 3). This result suggests that point estimates of recoil pressure are less discriminatory for a change in pulmonary elastic properties than is $\mathrm{K}$, which reflects the relative changes in recoil pressure and lung volume over the upper half of lung volume.

In their longitudinal study Corbin et $a^{21}$ reported a rate of decrease in $\mathrm{PL}_{90}$ (calculated by the present authors from table 3 of ref 21 ) of $11.0 \times 10^{-2} \mathrm{kPa} /$ year in smokers and $9.2 \times 10^{-2} \mathrm{kPa} /$ year in non-smokers. These rates, similar to each other, are about three times the rates of decrease in $\mathrm{PL}_{90}$ shown for our subjects in table 3. Corbin et al ${ }^{21}$ acknowledge that, because of systematic differences in their analysis of recoil pressure in the initial and in the final study, they may have overestimated the rate of decrease in $P_{L_{90}}$. Estimates for the increase in $\mathrm{K}$ may also be obtained from their values for $h-$ the half inflation pressure $(K$

Table 5 Lung volumes and FEV, (means with standard deviations in parentheses and percentages of predicted values in square brackets) for 39 smokers studied twice

\begin{tabular}{|c|c|c|c|}
\hline & Study I & Study 2 & Difference/y \\
\hline 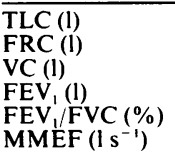 & $\begin{array}{cll}6.87 & (1.54) & {[102.2(11.3)]} \\
4.13 & (0.98) & {[112.4(17.4)]} \\
4.34 & (1.18) & {[96.9(12.7)]} \\
3.27 & (0.89) & {[98.7(16.8)]} \\
77.5 & (8.0) & \\
2.94 & (1.10) & {[90.7(31.4)]}\end{array}$ & $\begin{array}{ccc}7.18 & (1.56)[106.8(11.2)] \\
4.38 & (1.05)[119.6(21.0)] \\
4.24 & (1.11) & {[96.6(12.5)]} \\
3.01 & (0.85) & {[93.7(16.2)]} \\
74.9 & (10.2) & \\
2.61 & (1.14) & {[80.0(32.0)]}\end{array}$ & 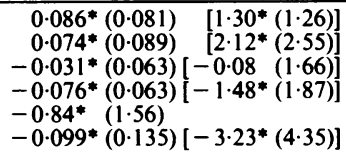 \\
\hline
\end{tabular}

${ }^{*} \mathrm{p}<0.005$ : significance of the difference over the interval of study (mean 3.5 (SD 0.5 ) years).

TLC - total lung capacity; FRC - functional residual capacity; VC_-vital capacity; FEV, -forced expiratory volume in one second; MMEFmaximum mid expiratory flow. 
$=\ln 2 / \mathrm{h}$ - -and, although their absolute values are systematically lower (owing to a different method of analysis) than for our own subjects, the rates of increase in $\mathrm{K}$ of $6.4 \times 10^{-2} \mathrm{kPa}^{-1} /$ year in smokers and $3.2 \times 10^{-2} \mathrm{kPa}^{-1} /$ year in non-smokers are similar to the values given in table 3 .

The results obtained in our longitudinal study of non-smokers ${ }^{11}$ showed that $\mathrm{K}$ increased as a function of its initial value, suggesting the use of an exponential, or logarithmic, model for expressing its increase with time. In the analyses given here the rate of increase in $\ln \mathrm{K}$ is greater in smokers than in non-smokers. The average obtained for $\Delta \ln \mathrm{K} / \mathrm{year}$ over the interval between the two studies (table 3 ) is greater than other estimates, but is probably a biased estimate and is limited in its application. Our statistical model (see table 4 and also under "Methods") used the absolute values for $\ln K$ and also allowed for significant variability between subjects. The estimate obtained for the annual increase in $\ln \mathrm{K}$ using this statistical model provides a weighted average value of the slope related to age; it was nearly twice the estimate obtained in the cross sectional study of smokers, although owing to a relatively large variance in both cases this difference did not reach significance. The significant $b_{2}$ age $\times \Delta$ age term (table 4) affects the slope of the linear regression of $\ln \mathrm{K}$ on age. As subjects become older this slope increases and is detected here because precision of comparison within subjects is greater than cross sectional comparisons between subjects.

In the comparison of longitudinal and cross sectional data for smokers inherent differences between these studies need to be considered. Smokers are a heterogeneous group, as shown by the significant between subject variation for $\ln \mathrm{K}$; and individuals would be expected to show different rates of change for any given parameter. In our cross sectional study of smokers individuals were selected who were not disabled. Thus subjects disabled because of smoking induced lung disease (predominantly older subjects) were excluded. This method of selection decreases the rate of change in lung function seen over time in a cross sectional study. It is therefore not surprising that the present longitudinal study of smokers showed a greater rate of change for distensibility and elastic recoil than was found in the cross sectional study of smokers. So far as their lung function was concerned, the 39 subjects included in the longitudinal study were representative of the original 101 subjects in the cross sectional study, and the relatively short interval between the two studies should have minimised loss of subjects because of the development of serious disability. But we cannot estimate how the data may have been affected had a larger proportion of the original subjects been studied twice.

The analysis given in table 4 is the basis for a model showing the increase in $\mathrm{K}$ as an exponential function of time (fig 3). The age coefficient from the logarithmic regression model $\left(b_{1}\right.$ in table 4$)$ is the reciprocal of the $\frac{\bar{\sigma}}{\bar{N}}$ time constant -44 years - while the SEM allows cal- $\frac{\pi}{\square}$

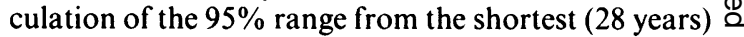
to the longest ( 105 years) time constant. The range for $\nRightarrow$ healthy non-smokers is from a cross sectional study of $\vec{\circ}$ 124 subjects, ${ }^{10}$ because this study covered a wider age range and included nearly four times as many subjects $\vec{\omega}$ as in the longitudinally studied non-smokers. In an average cigarette smoker $\mathrm{K}$ will be outside the normal $\overrightarrow{\vec{x}}$ range by his mid 40s, and a high initial value at the age $\vec{\omega}$ of 20 years, or a shortened time constant, means that $\dot{\omega}$ during the sixth decade he or she will achieve a value $\vec{v}$ for $K$ within the range found for patients with $O$ emphysema (diagnosed on clinical and radiological 은 grounds-Colebatch, unpublished observations). Because we excluded smokers with established pulmonary disease, we are likely to have underestimated the rate of increase in $\mathrm{K}$ in some smokers. The limits of the model (shortest time constant with highest initial $\vec{\varnothing}$ value and vice versa) are not, however, given in figure 9 3 . The range of time constants is such that some smokers would retain normal values for $\mathrm{K}$ throughout their lifespan.

The analysis given in figure 3 suggests how smokers who are susceptible to the emphysema inducing effect $\stackrel{\odot}{\varnothing}$ of cigarette smoke might be identified. To determine $\overrightarrow{\vec{P}}$ the time constant in an individual would require $\frac{\circ}{3}$ several measurements of $\mathrm{K}$ over an interval of 5-10 years. The exponential model suggests a simpler approach. Subjects with increased values for $\mathrm{K}$ have already identified themselves as having shortened time constants, and younger subjects who have $K$ values in $\underset{x}{\stackrel{2}{2}}$ the upper normal range are also likely to be in the susceptible group. (The distribution of the residuals of 3 . $\mathrm{K}$ in smokers supports the view that older subjects $\delta$ with increased values for $K$ are recruited predominantly from subjects whose $K$ values in their youth o initially lay in the upper normal range. ${ }^{12}$ ) It should also be noted that, because smoking does not decrease $\mathrm{K}$, 음 values for $\mathrm{K}$ in the lower normal range in figure 3 represent subjects who in their 20 s also had values in 0 . the lower normal range. The finding of an increased $N$ value for $\mathrm{K}$ would need to be confirmed in a sub- స్ sequent study and, where possible, by additional 0 studies covering several years.

Various observations support this model of a continuous increase in lung distensibility in cigarette $\stackrel{\mathbb{P}}{\rightarrow}$ smokers, a process that has emphysema as the end 0 result. In postmortem studies Thurlbeck ${ }^{34}$ found an $\overrightarrow{0}$ increase in the maximum lung volume and in airspace $\mathbb{8}$ size in lungs graded as showing only a trace of $\overrightarrow{\mathbb{D}}$ emphysema. He suggested that airspace enlargement may precede the destruction of alveolar tissue recognised as "emphysema." The observations of Silvers et 8 

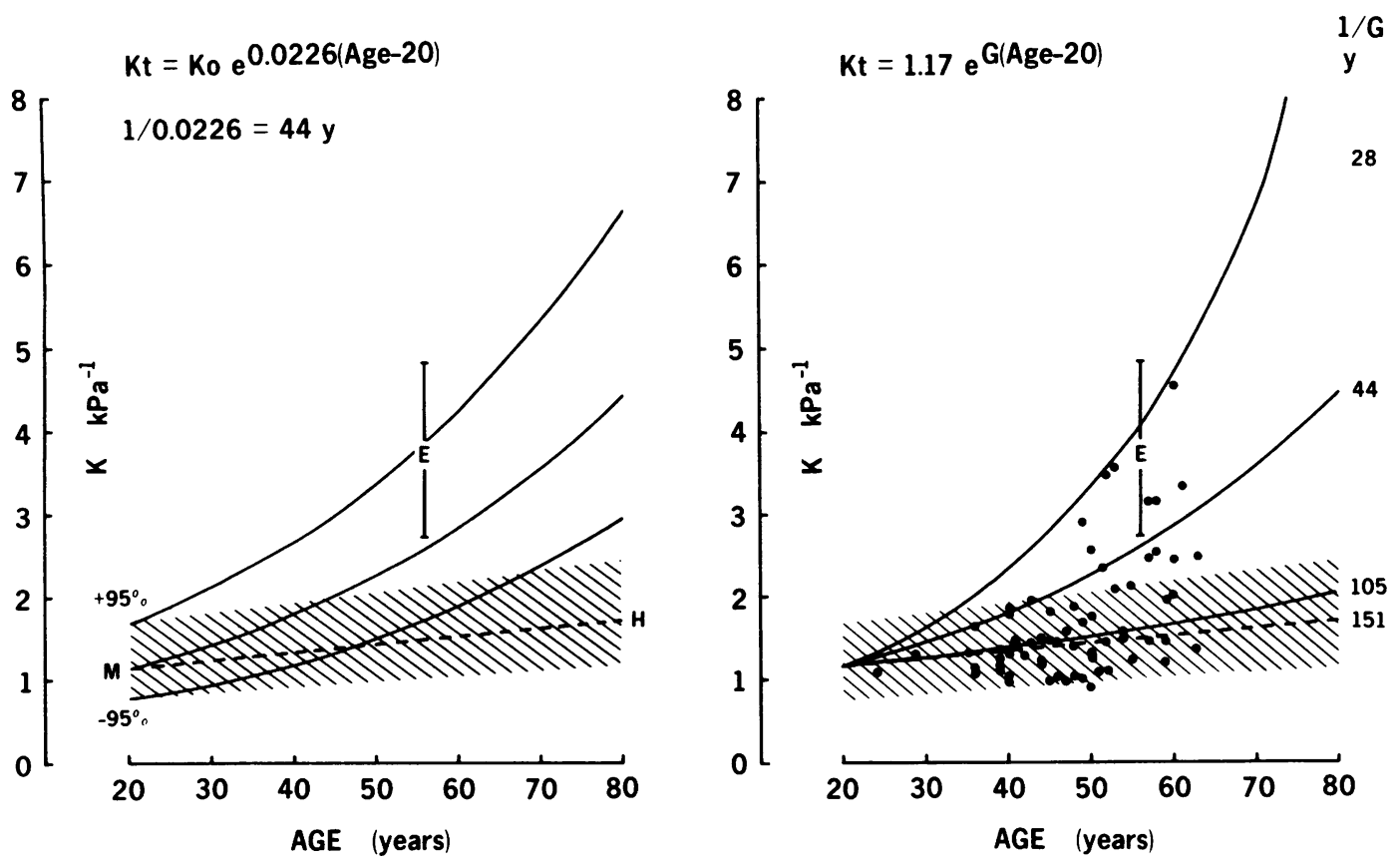

Fig 3 A model of the increase in the index of pulmonary distensibility $(K)$ as an exponential function of time. The interrupted line is the mean time constant for 124 healthy non-smokers ${ }^{10}$ and the shaded area the $95 \%$ confidence interval derived from the regression of In $K$ on age for these subjects. The range and standard deviation of values for $K$ found in 93 subjects with emphysema $(E)$ is shown (unpublished observations- see text). In the left hand panel curves are shown with the same time constant (44 years) and different initial values of $K$ at age 20 years $(K o)$. In the right hand panel the curves originate at the mean value for $K$ at age 20 years, and show the $95 \%$ range of time constants $(1 / G)$ for smokers as well as values for individual smokers in both studies. $K$ at any given time $(K t)$ is calculated according to the equations. $M-$ mean. For further discussion see text.

$a l^{5}$ and of Berend et $a l^{6}$ are also consistent with an increase in lung distensibility preceding the development of emphysema. In addition, an asymptomatic increase in distensibility has been found in a cross sectional study of smokers. ${ }^{12}$ This process of increasing distensibility implies-as detailed analysis elsewhere has shown ${ }^{2022}$ - that airways disease and emphysema are not causally related.

An increase in peripheral airspace size (that is, a decrease in the surface:volume ratio of the lungs) decreases the contribution of surface forces to lung recoil and thereby increases distensibility (increase in $\mathrm{K})$. Surface forces normally dominate the distensibility of air filled lungs and differences in tissue elasticity (as assessed in saline filled lungs) have no discernible effect on total lung distensibility. ${ }^{8}$ Thus increased distensibility in emphysema is likely to be directly related not to decreased tissue recoil or to the tissue destruction itself but to the accompanying enlargement of peripheral airspaces, an enlargement that is part of the definition of emphysema. ${ }^{23}$ In this respect, to use the term emphysema only when there is tissue destruction - the lesions of emphysema ${ }^{6}$ - may be misleading. In the assessment of emphysema there is a difference, in principle, between picture grading methods (which emphasise the most abnormal areas) and measurements of $\mathrm{Lm}^{7}$ (which exclude bullous lesions larger than $2 \mathrm{~cm}$ in diameter and include the more "normal" airspaces). Large emphysematous spaces in excised lungs remain inflated for days at very low transpulmonary pressure. 'Thus bullae probably contribute little to lung function during life other than as air filled, space occupying lesions and, in relating structure to distensibility, measurements of $\mathrm{Lm}$ appear to be preferable to measurements that reflect gross destructive lesions.

An increase in airspace size reflects changes to the fibrous framework of the lungs, probably caused by a relative increase in elastolytic activity in lung connective tissue.' This could occur, without any change in the total quantity of elastin or collagen, through a rearrangement of fibres that may reflect a greater turnover of elastin, ${ }^{24}$ as well as the normal stresses to which lung tissue is exposed throughout life. As is seen 
from the increase in $\mathrm{Lm}$ with age, " a similar process, but developing at a slower rate, takes place in normal aging. The development of imbalance between elastase and antielastase activity ${ }^{2}$ in smokers will be a chronic process ${ }^{1314}$ resulting in a gradual increase in airspace size and therefore in $\mathrm{K}$. Consequently the increase in airspace size, and therefore in $\mathrm{K}$, should be revealed as a continuous change over many years, as is suggested by the findings in the present study.

Because of its direct relationship with airspace size, $\mathrm{K}$ provides an appropriate index for identifying the development of emphysema during life..$^{22}$ High values for $\mathrm{K}$ identify smokers with large airspaces-the antecedent of emphysema. Moreover, longitudinal studies can identify smokers in whom $\mathrm{K}$ is increasing abnormally rapidly and who are therefore at risk of developing clinical emphysema.

The authors are indebted to Dr C A McGilchrist of the University of New South Wales for his advice on the use of a statistical model for treating longitudinal data, to the department of medical illustration, University of New South Wales, for photographing the illustrations, and to Mrs N Thomas for assistance in preparing the manuscript. This work was supported by grants from the National Health and Medical Research Council of Australia and the Clive and Vera Ramaciotti Foundations of New South Wales.

\section{References}

1 Snider GL. Pathogenesis of emphysema and chronic bronchitis. Med Clin North Am 1981;65:647-65.

2 Janoff A. Biochemical links between cigarette smoking and pulmonary emphysema. $J$ Appl Physiol 1983;55:285-93.

3 Thurlbeck WM. Internal surface area and other measurements in emphysema. Thorax 1967;22:483-96.

4 Thurlbeck WM. Post-mortem lung volumes. Thorax 1979;34:735-9.

5 Silvers GW, Petty TL, Stanford RE. Elastic recoil changes in early emphysema. Thorax 1980;35:490-5.

6 Berend N, Skoog C, Thurlbeck WM. Pressure-volume characteristics of excised human lungs: effects of sex, age and emphysema. J Appl Physiol 1980;49:558-65.

7 Greaves IA, Colebatch HJH. Elastic behavior and structure of normal and emphysematous lungs post mortem. Am Rev Respir Dis 1980;121:127-36.

8 Haber PS, Colebatch HJH, Ng CKY, Greaves IA. Alveolar size as a determinant of pulmonary disten-

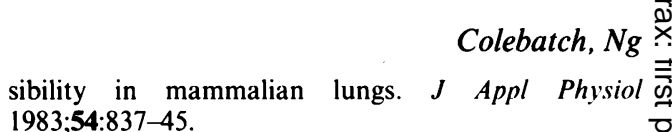

9 Colebatch HJH, Ng CKY, Nikov N. Use of an exponential function for elastic recoil. $J$ Appl Physiol के 1979;46:387-93

10 Colebatch HJH, Greaves IA, Ng CKY. Exponential 乞 analysis of elastic recoil and aging in healthy males and females. J Appl Physiol 1979;47:683-91

11 Colebatch $\mathrm{HJH}, \mathrm{Ng}$ CKY. A longitudinal study of pulmonary distensibility in healthy adults. Respir $\vec{\omega}$ Physiol 1986;65:1-11.

12 Colebatch HJH, Greaves IA, Ng CKY. Pulmonary distensibility and ventilatory function in smokers. Bull Eur Physiopathol Respir 1985;21:439-47.

13 Gadek JE, Hunninghake GW, Fells GA, Zimmerman $\omega$ RL, Keogh BA, Crystal RG. Evaluation of the $\vec{V}$ protease-antiprotease theory of human destructive $\mathrm{G}$ lung disease. Clin Respir Physiol 1980;16(suppl):27-40. 윽

14 Gadek JE, Fells GA, Zimmerman RL, Rennard SI, Crystal RG. Antielastases of the human alveolar structures. Implications for the protease-antiprotease theory of emphysema. J Clin Invest 1981;68:889-98.

15 Colebatch $\mathrm{HJH}$, Nail BS, $\mathrm{Ng}$ CKY. Computerized $\vec{\bullet}$ measurement of pulmonary conductance and elastic $\infty$ recoil. J Appl Physiol 1978;44:611-8.

16 Snedecor GW. Statistical methods. 5th ed. Ames, Iowa: Iowa State University Press, 1956.

17 McGilchrist CA, Sandland RL, Hills LJ. Estimation in regression models with stationary dependent errors. ฏै Communications in Statistics. Part A: Theory and $\stackrel{\circ}{\mathbb{D}}$ Methods 1981;10:2563-80.

18 McGilchrist CA, Sandland RL, Hennessy JL. $\overline{\bar{O}}$ Generalized inverses used in recursive estimation of the general linear model. Austral J Statist 1983;25:321-8.

19 Fletcher C, Peto R. The natural history of chronic airflow obstruction. Br Med J 1977;i:1645-8.

20 Colebatch HJH, Greaves IA. Chronic airflow 으 obstruction: Evolution of disordered function in $\underset{\times}{\beth}$ cigarette smokers. Med J Aust 1985;142:607-10.

21 Corbin RP, Loveland M, Martin RR, Macklem PT. A four year follow up study of lung mechanics in smokers. Am Rev Respir Dis 1979;120:293-304.

22 Greaves IA, Colebatch HJH. Observations on the pathogenesis of chronic airflow obstruction in smokers: implications for the detection of "early" lung $D$ disease [Editorial]. Thorax 1986;41:81-7.

23 Snider GL, Kleinerman J, Thurlbeck WM, Bengali ZH. The definition of emphysema. Report of a National $\mathrm{N}$ Heart, Lung, and Blood Institute, Division of Lung N Diseases Workshop. Am Rev Respir Dis 1985;132:182- N 5 .

24 Kucich U, Christner P, Lippmann M, et al. Utilization of a peroxidase antiperoxidase complex in ance enzyme-linked immunosorbent assay of elastin-derived $\overline{\mathbb{D}}$ peptides in human plasma. Am Rev Respir Dis $\stackrel{\mathscr{S}}{+}$ 1985;131:709-13. 